\title{
Inflammation-modulating cytokine profile and lipid interaction in HIV-related risk factors for cardiovascular diseases
}

This article was published in the following Dove Press journal:

Therapeutics and Clinical Risk Management

II November 2016

Number of times this article has been viewed

\author{
Elizabeth Gori ${ }^{1,2}$ \\ Takafira Mduluza ${ }^{3,4}$ \\ Mudavanhu Nyagura ${ }^{2}$ \\ Babill Stray-Pedersen ${ }^{5}$ \\ Zvenyika Alfred Gomo' \\ 'Chemical Pathology Department, \\ College of Health Sciences, \\ ${ }^{2}$ Preclinical Veterinary Studies \\ Department, Faculty of Veterinary \\ Sciences, ${ }^{3}$ Biochemistry Department, \\ University of Zimbabwe, Harare, \\ Zimbabwe; ${ }^{4}$ School of Laboratory \\ Medicine and Medical Sciences, \\ College of Health Sciences, University \\ of KwaZulu-Natal, Durban, South \\ Africa; ${ }^{5}$ Institute of Clinical Medicine, \\ University in Oslo, Oslo University \\ Hospital, Oslo, Norway
}

\footnotetext{
Correspondence: Elizabeth Gori Chemical Pathology Department, College of Health Sciences, University of Zimbabwe, Mazowe Street, PO Box Al78, Avondale, Harare, Zimbabwe Email egori@science.uz.ac.zw
}

\begin{abstract}
HIV infection and antiretroviral therapy (ART) are associated with changes in plasma levels of lipoproteins, thus posing the risk of cardiovascular complications in infected individuals. The alteration in plasma lipoprotein levels results from dysregulation of inflammation-modulating cytokines that control lipid metabolism. Little is understood regarding the relationship between the cytokines and serum lipid levels, which have been reported to be altered in adults receiving ART. The objective of this study was to describe the profiles of inflammation-modulating cytokines and their relationship to lipids as cardiovascular disease (CVD) risk factors in HIV infection. This observational cross-sectional study measured plasma levels of interleukin (IL)-10, tumor necrosis factor-alpha (TNF)- $\alpha$, IL-4, total cholesterol (TC), and high-density lipoprotein cholesterol (HDL-c) in HIV-infected and uninfected adults. A total of 219 HIV-infected participants were enrolled from an HIV treatment center; of them, 187 were receiving ART and 32 were ART naïve, while 65 were HIV-uninfected blood donors. HIV-infected individuals had higher levels of IL-10 (HIV-infected ART-naïve [ $P=0.0024]$ and ART-receiving $[P=0.033]$ ) than their uninfected counterparts. ART-naïve subjects had significantly higher plasma levels of IL-10 than ART-receiving subjects $(P=0.0014)$. No significant difference was observed in plasma levels of IL-4 and TNF- $\alpha$ across the three groups. Regarding plasma lipoproteins, HDL-c levels were reduced in HIV ART-naïve $(P=0.002)$ and ART-receiving $(P=0.015)$ subjects compared to HIV-uninfected subjects. Similarly, TC levels were lower in the HIV-infected than in the HIVuninfected group regardless of whether the patients were undergoing ART or not $(P<0.001)$. IL-10 levels correlated with TC levels in the HIV-uninfected group but not in the HIV-infected groups. Levels of HDL-c were reduced, while IL-10 plasma concentrations were elevated in HIV-infected individuals. A correlation observed in HIV-uninfected individuals between antiinflammatory cytokine IL-10 and TC was lost in HIV-infected individuals. Clinical significance of these differences needs to be ascertained with respect to HIV-related CVD risk.
\end{abstract}

Keywords: HIV, inflammation, cytokines, antiretroviral therapy, cardiovascular disease risk

\section{Introduction}

Infection with HIV is increasingly shown to be associated directly or indirectly with systemic inflammation and chronic immune activation which have damaging effects on the cardiovascular system. Some of the direct effects of HIV infection on cardiovascular integrity include microbial translocation ${ }^{1}$ and the effect of HIV protein Nef on ATP binding cassette transporter A1 (ABCA1), ${ }^{2}$ the mediator of cholesterol transport. ${ }^{3}$ Apart from the direct effects of HIV on cardiovascular integrity, some drugs for antiretroviral therapy (ART), mainly reverse transcriptase inhibitors (RTI) and protease inhibitors (PI), have been shown to cause metabolic changes such as dyslipidemia and 
insulin resistance. ${ }^{4-6}$ In addition, somatic changes such as lipodystrophy or lipoatrophy also occur. Both the metabolic and somatic changes occurring in HIV-infected individuals have been associated with an increased risk of cardiovascular disease (CVD), especially coronary artery disease and stroke. The multicenter prospective study on Data Collection on Adverse events of Anti-HIV Drugs (D:A:D) reported reduced high-density lipoprotein cholesterol (HDL-c) and ApoA levels in HIV-infected individuals as the major CVD risk factors due to altered lipid metabolism. ${ }^{7}$ These changes occur even in asymptomatic individuals with CD4 counts above 400 cells $/ \mathrm{mm}^{3}{ }^{8,9}$ The mechanism involved in the lipoprotein alteration is still unknown. Efforts to identify the atherogenic profile of metabolic syndrome related to HIV are ongoing and seemingly complex. Current data indicate the involvement of several factors, including direct effects of ART on lipid metabolism, ${ }^{10}$ endothelial and adipocyte cell function, ${ }^{11,12}$ and activation of proinflammatory cytokines. ${ }^{13-15}$

Cytokines play a major role in the metabolism of lipids. Accumulating data indicate that metabolism of lipids is under the control of some cytokines that regulate inflammation, but the exact mechanism is not clear. ${ }^{13,16,17}$ For instance, in lipodystrophy observed in HIV-infected individuals, the lipodystrophic adipose tissue manifests as an altered profile of secreted cytokines with increased tumor necrosis factor (TNF)- $\alpha$ and interleukin (IL)-6 levels. ${ }^{18}$ Lipodystrophy is linked as well to PI and RTI therapy in HIV treatment. ${ }^{13}$ In addition, insulin resistance is observed at adipocyte level, leading to increased rates of lipolysis and free fatty acids fluxes. ${ }^{19}$ The proinflammatory cytokine TNF- $\alpha$ leads to alterations in serum lipid levels by affecting three vital functions, namely the adipose tissue lipoprotein lipase, lipolysis, and the synthesis of hepatic fatty acids. ${ }^{17,20,21}$ Studies demonstrated that in addition to TNF- $\alpha$, other cytokines such as IL-1, interferon (IFN)- $\alpha$, and IL-10 can affect each of the lipid metabolism processes resulting in alterations in the levels of circulating lipids. ${ }^{21}$ In particular, IL-1, TNF- $\alpha$, and IFN- $\gamma$ have been shown to decrease the activity of lipoprotein lipase. $^{21,22}$ The anti-inflammatory cytokines IL-10 and IL-4 regulate the immune response by their inhibitory properties. Similarly, in lipid metabolism, IL-4 inhibits the stimulation of hepatic lipogenesis induced by proinflammatory cytokines TNF- $\alpha$, IL- 6 , and IL- $1 .{ }^{23} \mathrm{IL}-4$ counteracts the ability of these proinflammatory cytokines by preventing the increase in hepatic citrate levels. ${ }^{22}$ On the other hand, IL-10 stimulates the uptake of cholesterol from modified lipoproteins, and the efflux of cholesterol from the cell. Thus, IL-10 facilitates cholesterol uptake from modified lipoproteins and its transformation into foam cells. ${ }^{24,25}$ Essentially, various cytokines that act at different receptors can affect several separate processes, leading to altered lipid metabolism and consequently elevated serum lipid levels. ${ }^{17,22}$

Noteworthy, the adverse effects attributable to disturbances in lipid metabolism with complications affecting the cardiovascular system ${ }^{26}$ are more frequent in patients on ART than in HIV-negative individuals. It can be hypothesized that altered proinflammatory and anti-inflammatory cytokine production in HIV-infected individuals receiving ART could highlight the metabolic disorders observed in HIV-infected individuals. Very little has been done to determine whether these disturbances are associated with underlying cytokine profile alteration and treatment despite evidence of lipid alteration in HIV infection. This study was undertaken to explore the relationship of inflammation-modulating cytokine profiles in relation to lipid levels in HIV-infected population. We believe that the origin of CVD in this population is vascular inflammation and dyslipidemia.

\section{Materials and methods}

\section{Ethics statement}

Ethical approval to carry out this study was granted by the Joint Parirenyatwa Hospital and College of Health Sciences Research Ethics Committee (JREC Ref: 72/13) and the Medical Research Council of Zimbabwe (Ref: MRCZ/ A/1768). Individual written informed consent was obtained from all the willing participants.

\section{Data collection}

This was an analytical cross-sectional study on participants recruited from an HIV care and treatment center in Harare in Zimbabwe. Participants were approached consecutively when they came for their routine visits. An interviewer-administered questionnaire was used to gather the demographic and health information of participants at the time of enrollment into the study. Information with regard to history of stroke, heart disease, hypertension, or experience with tuberculosis (TB) infection after being diagnosed with HIV was collected. Participants' height and weight were measured, and body mass index (BMI) was calculated by dividing body weight $(\mathrm{kg})$ by squared height in meters $\left(\mathrm{m}^{2}\right)$. Blood pressure (systolic blood pressure [SBP] and diastolic blood pressure [DBP]) was measured by a standard mercury sphygmomanometer. Sixty-seven healthy HIV-negative blood specimens from donors at National Blood Services Zimbabwe made up the control group.

\section{Laboratory tests}

Analysis of CD4 lymphocyte counts was performed by flow cytometry. Quantification of HIV was done at the clinic 
using the COBAS AmpliPrep/COBAS TaqMan HIV-1test, version 2.0 (Hoffman-La Roche Ltd., Basel, Switzerland), as per manufacturer's instructions. The assay had a detection limit of 20 RNA copies/mL.

\section{Plasma cytokines level}

TNF- $\alpha$, IL-10, and IL-4 were measured in plasma by ELISA (R\&D System Europe Ltd, Abingdon, UK) according to manufacturer's instructions. All measurements were done in duplicates and values averaged for analysis.

\section{Lipid profile}

For measurement of lipids, blood samples were collected from participants into the tubes containing EDTA using venipuncture, and plasma was separated from cells by centrifugation within 12 hours of collection, aliquoted, and stored at $80^{\circ} \mathrm{C}$. Plasma total cholesterol (TC) and HDL-c concentrations were determined by Mindray ${ }^{\circledR}$ chemistry analyzer BS120 (Shenzhen, People's Republic of China).

\section{Statistical analysis}

Data analysis was performed using STATA $^{\circledR}$ V.13 (StataCorp, College Station, TX, USA). Descriptive statistics was used for demographic and clinical characteristics. Continuous variables were described as median and interquartile range (IQR) for non-normally distributed variables. Categorical variables were described by proportions and confidence intervals (CIs). The Mann-Whitney $U$-test was used to test differences between continuous variables among patients by HIV or ART status, if the variables were not normally distributed. Pearson's chi-square test was used to test for correlations between laboratory markers. Univariate (crude values) and multiple linear regression (adjusted coefficient) analyses were used to test for association or to identify variables which predict different levels of laboratory markers. The multiple linear regression analysis was used to control for confounding variables such as age, gender, and BMI. A $P$-value of 0.05 was considered significant.

\section{Results}

Of the approached 292 participants, 284 met the study criteria and were enrolled in this study. The majority $(85.4 \%)$ of the HIV-infected patients were receiving ART, while 14.6\% were ART naïve. Most (91\%) of the subjects on ART had received therapy for at least one year. The majority (90.9\%) were on first-line triple combination therapy comprising tenofovir (TDF), lamivudine (3TC), and nevirapine (NVP), 63.4\%; TDF, 3TC, and efavirenz (EFV), 17.2\%; and ART combinations with stavudine or zidovudine, $10.2 \%$. The remaining $9.1 \%$ had received ART including a PI. Demographic analysis showed that there was no difference in ages across the three groups. The CVD risk factors (SBP, DBP, and BMI) did not differ significantly between the groups. Laboratory parameters such as TC, low-density lipoprotein cholesterol (LDL-c), and HDL-c levels were significantly different across the three groups. Table 1 summarizes the demographics and clinical characteristics of the study subjects stratified by HIV and ART status.

Lower HDL-c levels were observed in HIV-uninfected individuals compared to ART-naïve $(P=0.002)$ and ARTexperienced $(P=0.015)$ individuals. No significant difference in HDL-c levels was observed within the HIV-infected groups $(P=0.208)$. Similarly, TC levels were lower in HIV-uninfected than in HIV-infected subjects, regardless of whether or not they had undergone ART. ART-naïve subjects had lower TC levels than the ART-receiving subjects $(P=0.005)$. There was a significant difference in the TC/HDL-c ratio across the

Table I Demographic and clinical characteristics of HIV-uninfected, and HIV-infected ART-receiving and ART-naïve participants

\begin{tabular}{|c|c|c|c|c|c|}
\hline Characteristic & $\begin{array}{l}\text { HIV-uninfected } \\
\text { group }(n=65)\end{array}$ & $\begin{array}{l}\text { HIV-infected } \\
\text { ART-receiving } \\
\text { group }(n=187)\end{array}$ & $\begin{array}{l}\text { HIV-infected } \\
\text { ART-naïve } \\
\text { group }(n=32)\end{array}$ & Total $(\mathbf{N}=\mathbf{2 8 4})$ & $P$-value \\
\hline Age (years) & $34(26-4 I)$ & $40(34-46)$ & $35(28-4 I)$ & $39(32-45)$ & $0.6 \mathrm{II}$ \\
\hline Gender: male & $20(31)$ & $40(21.4)$ & $9(28.1)$ & $69(24.3)$ & 0.418 \\
\hline BMI $\left(\mathrm{kg} / \mathrm{m}^{2}\right)$ & $21.74(20.55-27.4)$ & $23.5(20.8-26.8)$ & $22.5(21.0-26.2)$ & $23.28(20.83-27.1 \mathrm{I})$ & 0.962 \\
\hline Systolic blood pressure $(\mathrm{mmHg})$ & $120(110-137)$ & $122(113-137)$ & $124(110-136)$ & $122(111-137)$ & 0.911 \\
\hline Diastolic blood pressure $(\mathrm{mmHg})$ & $80(70-84)$ & $80(70-90)$ & $78(69-91)$ & $80(70-89)$ & 0.058 \\
\hline Hypertensive & $19(29)$ & $80(40.8)$ & $13(40.6)$ & $112(38.4)$ & 0.329 \\
\hline CD4 (cells $/ \mathrm{mm}^{3}$ ) & & 481 (305-669) & $421(344-647)$ & $45 I(316-669)$ & $0.98 \mathrm{I}$ \\
\hline Undetectable VL & & $150(80.2)$ & 0 & $150(80.2)$ & $<0.001$ \\
\hline Stroke & & $8(4.3)$ & 0 & $8(4.3)$ & 0.210 \\
\hline Heart disease & & II (5.8) & 0 & II (5.8) & 0.293 \\
\hline Smoking & & $6(3.2)$ & 0 & $6(3.2)$ & 0.238 \\
\hline Tuberculosis & & $65(34.7)$ & $2(6.3)$ & $67(30.6)$ & 0.004 \\
\hline
\end{tabular}

Note: Data are presented as median (IQR) or N (\%).

Abbreviations: BMI, body mass index; VL, viral load; IQR, interquartile range; $A R T$, antiretroviral therapy. 
Table 2 Plasma levels of cytokines and lipids in HIV-infected ART-receiving and ART-naïve participants and HIV-uninfected participants

\begin{tabular}{|c|c|c|c|c|c|c|}
\hline Parameter & $\begin{array}{l}\text { HIV-uninfected } \\
\text { group }\end{array}$ & $\begin{array}{l}\text { HIV-infected } \\
\text { ART-naïve group }\end{array}$ & $\begin{array}{l}\text { HIV-infected } \\
\text { ART-receiving group }\end{array}$ & PI & $\mathbf{P 2}$ & P3 \\
\hline IL-I0 (pg/mL) & $1.42 \pm 0.12$ & $1.77 \pm 0.5$ & $1.57 \pm 0.46$ & $0.0024 *$ & $0.033^{*}$ & $0.014 *$ \\
\hline IL-4 (pg/mL) & $1.84 \pm 0.19$ & $1.82 \pm 0.33$ & $1.73 \pm 0.23$ & 0.060 & 0.170 & 0.465 \\
\hline TNF- $\alpha(p g / m L)$ & $2.12 \pm 0.55$ & $2.17 \pm 0.59$ & $2.15 \pm 0.53$ & 0.190 & 0.576 & 0.080 \\
\hline IL-I0:TNF- $\alpha$ & $1.72 \pm 1.67$ & $1.79 \pm 0.9$ & $1.73 \pm 1.72$ & $0.036^{*}$ & $0.046^{*}$ & 0.063 \\
\hline IL-4:TNF- $\alpha$ & $1.70 \pm 0.87$ & $1.57 \pm 0.76$ & $\mathrm{I} .5 \mathrm{I} \pm 0.82$ & 0.084 & 0.136 & 0.321 \\
\hline TC (mg/dL) & I $55.67 \pm 43.32$ & $116.6 \pm 31.80$ & $139.64 \pm 43.99$ & $<0.00 I^{*}$ & $0.005^{*}$ & $<0.001 *$ \\
\hline $\mathrm{HDL}(\mathrm{mg} / \mathrm{dL})$ & $51.90 \pm 16.74$ & $42.82 \pm 15.05$ & $44.54 \pm 16.59$ & $0.002^{*}$ & 0.0508 & $0.015^{*}$ \\
\hline TC:HDL & $3.15 \pm 0.91$ & $3.31 \pm 1.26$ & $3.90 \pm 3.35$ & 0.052 & $0.0026^{*}$ & $0.0138^{*}$ \\
\hline
\end{tabular}

Notes: Data are presented as mean \pm SD. PI, comparison between HIV-uninfected and ART-naïve groups; P2, comparison between ART-naïve and ART-receiving groups; $\mathrm{P} 3$, comparison between HIV-uninfected and ART-receiving groups. $* P<0.05$.

Abbreviations: IL, interleukin; ART, antiretroviral therapy; TNF- $\alpha$, tumor necrosis factor-alpha; TC, total cholesterol; HDL, high-density lipoprotein; SD, standard deviation; ART, antiretroviral therapy.

groups. HIV-infected ART-receiving group had the highest TC/HDL-c ratio (Table 2).

Plasma levels of IL-10 were significantly higher in the HIV-infected ART-naïve $(P=0.0024)$ and ART-receiving $(P=0.033)$ subjects than in their uninfected counterparts. Within the HIV-infected group, ART-naïve had significantly higher plasma levels of IL-10 than ART-receiving group $(P=0.0014)$. No significant difference was observed in plasma levels of IL- 4 and TNF- $\alpha$ across the three groups, but levels of IL-4 were lower and those of TNF- $\alpha$ were higher in the HIV-infected groups (Table 2).

\section{Association between plasma levels of cytokines and lipids}

There was a negative correlation between IL-10 and TC in HIV-uninfected group $(r=0.377, P=0.018)$. This correlation was lost in both HIV-infected groups (ART naïve $[P=0.068]$ and ART receiving $[P=0.860])$. No other correlation was observed between cytokines and lipids in the HIV-infected groups. There was significant correlation between IL-10 and TNF- $\alpha$ across all the groups (Tables 3-5). Unlike in

Table 3 Correlations among cytokines and lipid parameters in HIV-uninfected participants

\begin{tabular}{llllll}
\hline $\begin{array}{l}\text { Plasma } \\
\text { parameter }\end{array}$ & IL-4 & TNF- $\alpha$ & TC & HDL & TC/HDL \\
\hline IL-I0 (pg/mL) & 0.1892 & 0.3162 & -0.3770 & -0.0288 & 0.1365 \\
& $P=0.0562$ & $P=0.0109 *$ & $P=0.018^{*}$ & $P=0.1064$ & $P=0.2984$ \\
IL-4 (pg/mL) & - & 0.4976 & -0.1107 & -0.0933 & $-0.083 \mathrm{I}$ \\
& & $P=0.0003^{*}$ & 0.4590 & $P=0.5326$ & $P=0.5830$ \\
TNF- $\alpha(\mathrm{pg} / \mathrm{mL})$ & - & - & 0.1392 & $-0.074 \mathrm{I}$ & -0.0499 \\
& & & $P=0.2845$ & $P=0.5704$ & $P=0.4732$ \\
$\mathrm{TC}(\mathrm{mg} / \mathrm{dL})$ & - & - & - & 0.2661 & 0.2647 \\
& & & & $P=0.0382^{*}$ & $P=0.0410^{*}$ \\
$\mathrm{HDL}(\mathrm{mg} / \mathrm{dL})$ & - & - & - & - & -0.5005 \\
& & & & & $P<0.000 I^{*}$ \\
\hline
\end{tabular}

Notes: *Represents significant $P$-values. $P<0.05$.

Abbreviations: IL, interleukin; TNF- $\alpha$, tumor necrosis factor-alpha; TC, total cholesterol; HDL, high-density lipoprotein.
HIV-infected groups, no correlation was observed between IL-10 and IL-4 in the HIV-uninfected group. With regard to the lipids, there was a significant correlation between TC and HDL-c in the HIV-uninfected group $(r=0.2661$, $P=0.0382$ ), but the correlation was not observed in both the HIV ART-naïve $(P=-0.3020)$ and HIV ART-receiving groups $(P=0.0706)$.

\section{Discussion}

HIV infection is associated with changes in plasma levels of lipoproteins. The process occurs as a result of alteration in lipoprotein metabolism induced by cytokines that mediate the immune response, including TNF- $\alpha$, IL-1 beta, and the IFN. ${ }^{17,20}$ The inflammation-modulating cytokines, IL-10, IL-4, and TNF- $\alpha$, are implicated both in the pathogenesis and morbidities of HIV infection, and their alteration may have a bearing in the development of CVDs in HIV infection.

In the present study, IL-10 levels were higher while IL-4 levels were lower in the HIV-infected groups. In individuals with HIV infection, higher levels of IL-10 have

Table 4 Correlations among cytokines and lipid parameters in HIV-infected ART-naïve participants

\begin{tabular}{llllll}
\hline $\begin{array}{l}\text { Plasma } \\
\text { parameter }\end{array}$ & IL-4 & TNF- $\alpha$ & TC & HDL & TC/HDL \\
\hline $\mathrm{IL}-\mathrm{I0}(\mathrm{pg} / \mathrm{mL})$ & 0.2922 & 0.6187 & -0.2270 & -0.3895 & -0.0432 \\
& $P=0.043 \mathrm{I}^{*}$ & $P=0.0002 *$ & $P=0.068$ & $P=0.0543$ & $P=0.8376$ \\
$\mathrm{IL}-4(\mathrm{pg} / \mathrm{mL})$ & - & 0.0734 & -0.2337 & -0.2979 & -0.1074 \\
& & $P=0.438$ & $P=0.5345$ & $P=0.148 \mathrm{I}$ & $P=6094$ \\
$\mathrm{TNF}-\alpha(\mathrm{pg} / \mathrm{mL})$ & - & - & -0.1895 & -0.3645 & -0.0082 \\
& & & $P=0.5083$ & $P=0.0733$ & $P=9689$ \\
$\mathrm{TC}(\mathrm{mg} / \mathrm{dL})$ & - & - & - & -0.3020 & 0.0967 \\
& & & & $P=0.1423$ & $P=0.6456$ \\
$\mathrm{HDL}(\mathrm{mg} / \mathrm{dL})$ & - & - & - & - & -0.5902 \\
& & & & & $P=0.0019 *$ \\
\hline
\end{tabular}

Notes: *Represents significant $P$-values. $P<0.05$.

Abbreviations: IL, interleukin; TNF- $\alpha$, tumor necrosis factor-alpha; TC, total cholesterol; HDL, high-density lipoprotein; ART, antiretroviral therapy. 
Table 5 Correlations among cytokines and lipid parameters in HIV-infected ART-receiving participants

\begin{tabular}{|c|c|c|c|c|c|}
\hline $\begin{array}{l}\text { Plasma } \\
\text { parameter }\end{array}$ & IL-4 & TNF- $\alpha$ & TC & HDL & TC/HDL \\
\hline \multirow[t]{2}{*}{ IL-I0 (pg/mL) } & 0.0195 & 0.2650 & 0.0131 & -0.0259 & 0.0526 \\
\hline & $P=0.058$ & $P<0.000 I^{*}$ & $P=0.8600$ & $P=0.7509$ & $P=0.5|8|$ \\
\hline \multirow[t]{2}{*}{$\mathrm{IL}-4$ (pg/mL) } & - & 0.1041 & 0.0655 & -0.0314 & 0.0511 \\
\hline & & $P=0.332$ & $P=3757$ & $P=7004$ & $P=0.5305$ \\
\hline \multirow[t]{2}{*}{ TNF- $\alpha(p g / m L)$} & - & - & 0.0880 & 0.0650 & -0.0026 \\
\hline & & & $P=2337$ & $P=4246$ & $P=9747$ \\
\hline \multirow[t]{2}{*}{$\mathrm{TC}(\mathrm{mg} / \mathrm{dL})$} & - & - & - & 0.1466 & 0.2215 \\
\hline & & & & $P=0.0706$ & $P=0.0059 *$ \\
\hline \multirow[t]{2}{*}{$\mathrm{HDL}(\mathrm{mg} / \mathrm{dL})$} & - & - & - & - & -0.4192 \\
\hline & & & & & $P<0.000$ I* \\
\hline
\end{tabular}

Note: $* P<0.05$.

Abbreviations: IL, interleukin; TNF- $\alpha$, tumor necrosis factor-alpha; TC, total cholesterol; HDL, high-density lipoprotein; ART, antiretroviral therapy.

been shown to be associated with secondary infection and advanced disease. In this population, a number of participants reported taking medication other than those included in ART, and about $35 \%$ reported previous or current TB infection. This indicates presence of secondary or opportunistic infections contributes to higher levels of IL-10. The majority of HIV-infected individuals in this population seek treatment late, as evidenced by the opportunistic infections. High levels of IL-10 have been recorded in the serum of infected people at late stages of the disease. ${ }^{27,28}$ Furthermore, the observed higher levels of IL-10 in ART-naïve patients compared with those receiving ART may be due to untreated immunological disease. Previous research documents that the significance of IL-10 in the course of disease lies in its ability to both decrease and increase viral replication under the influence of other cytokines such as proinflammatory TNF- $\alpha$.

This study observed a correlation between IL-10 and TC in the HIV-negative participants. Interestingly, this correlation was lost in both HIV-infected groups. This finding could suggest a role for IL-10 in the metabolism of some TC components, such as HDL-c and LDL-c, and their accompanying alteration in serum levels in HIV infection. Moraitis et $\mathrm{al}^{29}$ reported elevated levels of IL-10 as a cause of dyslipidemia and HDL-c deficiency in HIV-infected individuals. Noteworthy, the change in plasma levels of lipoproteins has been reported as a process occurring due to an alteration in lipoprotein metabolism induced by cytokines that mediate the immune response. ${ }^{17}$ Thus, the results of our study seem to support this notion. Of note, the relationship between IL-10 and TC in ART-naïve group was different from that observed in HIV-uninfected group. This condition was observed despite both groups having significantly lower rates of reported previous or current experience with TB infection compared to ART-receiving individuals.
Although some studies have reported lower TC levels in HIV/ TB coinfection, ${ }^{30}$ studies by Adewole et al, ${ }^{8}$ Denue et al,,${ }^{31}$ and Malapati et $\mathrm{a}^{32}$ did not find significant differences in TC levels between HIV patients with TB coinfection and HIV-infected counterparts without the coinfection. Previous studies reported enhanced dyslipidemia in HIV/TB coinfection in the absence of ART, while improved lipid profile was observed in the coinfected individuals receiving NVPbased ART than in those receiving EFV-based ART. ${ }^{33,34}$ The majority of participants in this study were on NVP-based ART; however, it is not clear whether infection with TB had an effect on TC levels, and would need further investigation. Conflicting data about the role of IL-4 have been reported. Similar to findings by Piddubna et al, ${ }^{27}$ we found low levels of IL-4 in HIV infection, but other studies reported an increase in its concentration with infection progression. ${ }^{35,36}$

With regard to pro- and anti-inflammatory cytokine relationship, we showed that IL-10 was correlated with TNF- $\alpha$ in all the groups. It is worth noting that viral multiplication appears to be an important factor in deciding the serum concentrations and the correlation between pro- and antiinflammatory cytokines. The HIV ART-naïve subjects had a significantly strong correlation between IL-10 and TNF- $\alpha$ ( $r=0.6187, P=0.0002$ ), while the ART-experienced subjects had medium correlation $(r=0.2650, P<0.0001)$. The HIVinfected ART-naïve subjects had significantly higher viral load, which is expected of individuals not on antiretroviral drugs that decrease viral multiplication. In this population, ART initiation was based on the immunological profile of CD4 (ie, when CD4 count falls to around $350 \mathrm{cell} / \mathrm{mm}^{3}$ ); hence, viral multiplication would be expected to be active in the ART-naïve subjects.

Findings from studies performed in the general population with a history of CVD showed that the plasma concentration of TNF- $\alpha$ was reportedly higher and had strong association with reduced levels of HDL-c. ${ }^{37} \mathrm{We}$ did not find significant differences in the levels of the proinflammatory cytokines between HIV-infected and -uninfected groups. This study also did not find significant correlation between TNF- $\alpha$ and lipid parameters including HDL-c in all the groups. Our findings are consistent with those of a few studies that sought to find relationship of TNF- $\alpha$ with lipodystrophy and failed to find any association. In a related study conducted in children, TNF- $\alpha$ was not associated with lipids. ${ }^{38}$ Other studies reported an association between TNF- $\alpha$ and lipids in the patients with lipodystrophy..$^{39}$ In Zimbabwean population, the prevalence of lipodystrophy is reportedly low and has been strongly associated with the use of stavudine-containing antiretroviral regimens. ${ }^{40}$ In the current study, the use of 
stavudine was low, as this drug is being phased out of the market. Seemingly, changes in TNF- $\alpha$ cytokine levels are associated with alteration in the lipid metabolism during the course of HIV infection. For instance, in a longitudinal study done by Cervia et $\mathrm{al}^{38}$ over 48 weeks, the observed decrease in TNF- $\alpha$ was associated with reduced TC/HDL-c ratio. This reassures that reductions in the TNF- $\alpha$ levels with successful ART are also associated with an improved lipid profile. In agreement with the analysis of data from two large patient cohorts, World Health Organization study monitoring trends and determinants of CVD (WHO-MONICA) and the Antiprotéases Cohorte (APROCO),${ }^{41}$ the present study showed that patients with HIV infection have significantly higher TC/HDL-c ratio than uninfected subjects, suggesting a greater risk for CVD. In other studies, these lipid changes have been found to be statistically associated with changes in TNF- $\alpha$ levels in HIV-infected individuals, ${ }^{13}$ a relationship which was not observed in this study.

In keeping with previous studies, ${ }^{42} \mathrm{TC}$ and HDL-c serum levels were within normal values in all the groups, but HIVinfected subjects had significantly lower HDL-c levels. This supports the notion that HIV infection by itself leads to impaired metabolism of lipoproteins which may in turn lead to CVDs. Calmy et al point to possible molecular mechanisms underlying the proatherosclerotic effect of HIV-RNA in the cascade leading to a cardiovascular event. ${ }^{43,44}$ In the present study, HIV-infected subjects on ART had higher HDL-c levels, implying improved lipid profile after treatment. Some researchers have speculated that the reduced HDL-c levels observed during inflammation may be a consequence of increased catabolism arising from high serum concentrations of amyloid A protein that replaces ApoAl as an apolipoprotein in HDL-c particles. Moreover, the HIV-infected groups had higher IL-10 and reduced HDL-c levels, a finding that agrees with studies on experimental animals which demonstrated that subcutaneous injection of recombinant human IL-10 swiftly decreases HDL-c and LDL levels, and the condition gets reversed once the injection is discontinued. ${ }^{29}$ Thus, IL-10 is a potential modulator of lipoprotein levels and acts as an effective biomarker for CVDs.

\section{Limitations and strengths}

This study had limitations with regard to the unavailability of CVD events and limited number of traditional CVD risk factors to associate with the assessed cytokines as well as reported experience with TB infection after HIV. These factors may have an impact on the interpretation of our results. Thus, the findings should be interpreted within the context of this study and its limitations. The strengths of the study were its high statistical power and the inclusion of HIV-uninfected group to enable comparison with the infected subjects.

\section{Conclusion}

This study observed a loss in relationship between antiinflammatory cytokine IL-10 and TC from uninfected to HIV-infected groups regardless of ART. Based on the lipid profile, it was observed that HIV-infected individuals receiving ART are at an increased risk of developing CVD. Further studies of prospective longitudinal design should be performed to determine the impact of the changes in IL-10 and TC levels on CVD risk in HIV-infected individuals.

\section{Acknowledgments}

The authors thank Letten Foundation, Norway, for funding this study, the staff and students of the University of Zimbabwe, Departments of Preclinical Veterinary Studies and Biochemistry, for the technical and academic support, the staff and patients of Newlands Clinic for their participation in the study, and Mercy Marimirofa for providing assistance in statistical analysis.

\section{Author contributions}

The experiments were conceived and designed by ZAG, TM, BS-P, and EG and were performed by EG. The data were analyzed by EG, TM, and MN. Reagents/materials/analysis tools were contributed by BS-P, TM, and EG. The paper was written by EG and statistical analysis was done by EG and TM. ZAG, TM, MN, and BS-P critically reviewed the paper. All authors contributed toward data analysis, drafting and critically revising the paper and agree to be accountable for all aspects of the work.

\section{Disclosure}

The authors report no conflicts of interest in this work.

\section{References}

1. Trøseid M, Manner IW, Pedersen KK, Haissman JM, Kvale D, Nielsen SD. Microbial translocation and cardiometabolic risk factors in HIV infection. AIDS Res Hum Retroviruses. 2014;30(6):514-522.

2. Cui HL, Ditiatkovski M, Kesani R, et al. HIV protein Nef causes dyslipidemia and formation of foam cells in mouse models of atherosclerosis. FASEB J. 2014;28(7):2828-2839.

3. Crowe SM, Westhorpe CLV, Mukhamedova N, Jaworowski A, Sviridov D, Bukrinsky M. The macrophage: the intersection between HIV infection and atherosclerosis. J Leukoc Biol. 2010;87(4):589-598.

4. Estrada V, Portilla J. Dyslipidemia related to antiretroviral therapy. AIDS Rev. 2011;13(1):49-56.

5. Feeney ER, Mallon PW. HIV and HAART-associated dyslipidemia. Open Cardiovasc Med J. 2011;5:49-63. 
6. Troll JG. Approach to dyslipidemia, lipodystrophy, and cardiovascular risk in patients with HIV infection. Curr Atheroscler Rep. 2011;13(1): 51-56.

7. Friis-Møller N, Weber R, Reiss P, et al. Cardiovascular disease risk factors in HIV patients - association with antiretroviral therapy. Results from the DAD study. AIDS. 2003;17(8):1179-1193.

8. Adewole OO, Eze S, Ye B, et al. Lipid profile in HIV/AIDS patients in Nigeria. Afr Health Sci. 2010;10(2):144-149.

9. Souza SJ, Luzia LA, Santos SS, Rondó PH. Lipid profile of HIV-infected patients in relation to antiretroviral therapy: a review. Rev Assoc Med Bras. 2013;59(2):186-198.

10. Podzamczer D. Lipid metabolism and cardiovascular risk in HIV infection: new perspectives and the role of nevirapine. AIDS Rev. 2013; 15(4):195-203.

11. Xiao Q, Kiechl S, Patel S, et al. Endothelial progenitor cells, cardiovascular risk factors, cytokine levels and atherosclerosis-results from a large population-based study. PLoS One. 2007;2(10):e975.

12. Andrade AC, Cotter BR. Endothelial function and cardiovascular diseases in HIV infected patient. Braz J Infect Dis. 2006;10(2):139-145.

13. Ledru E, Christeff N, Patey O, de Truchis P, Melchior JC, Gougeon ML. Alteration of tumor necrosis factor-alpha T-cell homeostasis following potent antiretroviral therapy: contribution to the development of human immunodeficiency virus-associated lipodystrophy syndrome. Blood. 2000;95(10):3191-3198.

14. Crowe SM, Hoy JF. Are monocytes the canary in the coal mine for HIV-related atherosclerosis? J Infect Dis. 2012;206(10):1491-1493.

15. Gibellini D, Borderi M, Clo A, et al. HIV-related mechanisms in atherosclerosis and cardiovascular diseases. J Cardiovasc Med. 2013; 14(11):780-790

16. Nunez EA, Christeff N. Steroid hormone, cytokine, lipid and metabolic disturbances in HIV infection. Baillieres Clin Endocrinol Metab. 1994;8(4):803-824.

17. Feingold KR, Soued M, Serio MK, Moser AH, Dinarello CA, Grunfeld C. Multiple cytokines stimulate hepatic lipid synthesis in vivo. Endocrinology. 1989;125(1):267-274.

18. Johnson JA, Albu JB, Engelson ES, et al. Increased systemic and adipose tissue cytokines in patients with HIV-associated lipodystrophy. Am J Physiol Endocrinol Metab. 2004;286(2):E261-E271.

19. Barbaro G, Iacobellis G. Metabolic syndrome associated with HIV and highly active antiretroviral therapy. Curr Diab Rep. 2009;9(1): 37-42.

20. Feingold KR, Grunfeld C. Role of cytokines in inducing hyperlipidemia. Diabetes. 1992;41:97-101.

21. McLaren JE, Michael DR, Ashlin TG, Ramji DP. Cytokines, macrophage lipid metabolism and foam cells: implications for cardiovascular disease therapy. Prog Lipid Res. 2011;50(4):331-347.

22. Aberg JA. Cardiovascular complications in HIV management: past, present, and future. J Acquir Immune Defic Syndr. 2009;50(1):54-64.

23. Tsao CH, Shiau MY, Chuang PH, Chang YH, Hwang J. Interleukin-4 regulates lipid metabolism by inhibiting adipogenesis and promoting lipolysis. J Lipid Res. 2014;55(3):385-397.

24. Han X, Kitamoto S, Wang H, Boisvert WA. Interleukin-10 overexpression in macrophages suppresses atherosclerosis in hyperlipidemic mice. FASEB J. 2010;24(8):2869-2880.

25. Han X, Kitamoto S, Lian Q, Boisvert WA. Interleukin-10 facilitates both cholesterol uptake and efflux in macrophages. J Biol Chem. 2009; 284(47):32950-32958.

26. Nguemaïm NF, Mbuagbaw J, Nkoa T, et al. Serum lipid profile in highly active antiretroviral therapy-naïve HIV-infected patients in Cameroon: a case-control study. HIV Med. 2010;11(6):353-359.

27. Piddubna AI, Chemych MD. IL-4, IL-10, TNF- $\alpha$ profile and immunological changes in North-Eastern Ukrainian HIV-infected individuals. HIV AIDS Rev. 2013;12:68-72.

28. Orsilles MA, Pieri E, Cooke P, Caula C. IL-2 and IL-10 serum levels in HIV-1-infected patients with or without active antiretroviral therapy. APMIS. 2006;114(1):55-60.
29. Moraitis AG, Freeman LA, Shamburek RD, et al. Elevated interleukin-10: a new cause of dyslipidemia leading to severe HDL-c deficiency. J Clin Lipidol. 2015;9(1):81-90.

30. Padmapriyadarsini C, Ramesh Kumar S, Terrin N, et al. Dyslipidemia among HIV-infected patients with tuberculosis taking once-daily nonnucleoside reverse-transcriptase inhibitor-based antiretroviral therapy in India. Clin Infect Dis. 2011;52(4):540-546.

31. Denue BA, Alkali MB, Abjah AU, Kida IM, Ajayi B, Fate BZ. Changes in lipid profiles and other biochemical parameters in HIV-1 infected patients newly commenced on HAART regimen. Infect Dis. 2013;6: $7-14$.

32. Malapati B, Patel B, Shah RM, et al. Changes in lipid profiles and other biochemical parameters in HIV-1 infected patients. Int J Med Sci Public Health. 2014;3(7):813-817.

33. Tanjeko AT, Kwenti TE, Nkume FA, Chongsi ME, Mbuntum JF, Bain LE. Changes in lipid profile and body mass index in HIV/AIDS patients on antiretroviral and anti-tuberculosis therapies in Cameroon. Res J Pharm Biol Chem Sci. 2014;5(6):1275-1283.

34. Mankhatitham W, Luaengniyomkul A, Manosuthi W. Lipid profile changes in Thai HIV and tuberculosis co-infected patients receiving non-nucleoside reverse transcriptase inhibitors-based antiretroviral therapy. J Med Assoc Thai. 2012;95(2):163-169.

35. Imami N, Antonopoulos C, Hardy GAD, Gazzard B, Gotch FM. Assessment of type 1 and type 2 cytokines in HIV type 1-infected individuals: impact of highly active antiretroviral therapy. AIDS Res Hum Retroviruses. 1999;15(17):1499-1508.

36. Vecchiet J, Dalessandro M, Travasi F, et al. Interleukin-4 and interferongamma production during HIV-1 infection and changes induced by antiretroviral therapy. Int J Immunopathol Pharmacol. 2003;16(2): $157-166$.

37. Mendall MA, Patel P, Asante M, et al. Relation of serum cytokine concentrations to cardiovascular risk factors and coronary heart disease. Heart. 1997;78(3):273-277.

38. Cervia JS, Chantry CJ, Hughes MD, Iii WAM, Hodge J, Borum P. Associations of proinflammatory cytokine levels with lipid profiles, growth, and body composition in HIV-infected children initiating or changing antiretroviral therapy. Pediatr Infect Dis J. 2010;29(12):1118-1122.

39. Maher B, Lloyd J, Wilkins EGL, et al. Lipodystrophy in patients with HIV-1 infection: effect of stopping protease inhibitors on TNF- $\alpha$ and TNF-receptor levels, and on metabolic parameters. Antivir Ther. 2004; 9(6):879-887.

40. Nemaura T, Dhoro M, Nhachi C, Kadzirange G, Chonzi P, Masimirembwa C. Valuation of the prevalence, progression and severity of common adverse reactions (lipodystrophy, CNS, peripheral neuropathy, and hypersensitivity reactions) associated with antiretroviral therapy (ART) and anti-tuberculosis treatment in outpatients in Zimbabwe. J AIDS Clin Res. 2013;4:203.

41. Saves M, Chene G, Ducimetiere P, et al. Risk factors for coronary heart disease in patients treated for human immunodeficiency virus infection compared with the general population. Clin Infect Dis. 2003;37(2): 292-298.

42. Pontes-Cardoso LCR, Souza LR, Peraçoli MTS, Pereira PCM. Cytokines profile and clinical-metabolic alterations in HIV-1-infected individuals with and without lypodistrophy. J Venom Anim Toxins Trop Dis. 2007;13(2):509-526.

43. Oka F, Naito T, Oike M, et al. Correlation between HIV disease and lipid metabolism in antiretroviral-nave HIV-infected patients in Japan. $J$ Infect Chemother. 2012;18(1):17-21.

44. Calmy A, Gayet-Ageron A, Montecucco F, et al. HIV increases markers of cardiovascular risk: results from a randomized, treatment interruption trial. AIDS. 2009;23(8):929-939. 


\section{Publish your work in this journal}

Therapeutics and Clinical Risk Management is an international, peerreviewed journal of clinical therapeutics and risk management, focusing on concise rapid reporting of clinical studies in all therapeutic areas, outcomes, safety, and programs for the effective, safe, and sustained use of medicines. This journal is indexed on PubMed Central, CAS,

EMBase, Scopus and the Elsevier Bibliographic databases. The manuscript management system is completely online and includes a very quick and fair peer-review system, which is all easy to use. Visit http://www.dovepress.com/testimonials.php to read real quotes from published authors.

Submit your manuscript here: http://www.dovepress.com/therapeutics-and-clinical-risk-management-journal 